Vol. 3, No. 2, 2017

\author{
Anatoly Zhygalov ${ }^{1}$, Vadym Stupnytskyy ${ }^{2}$ \\ 1 “Promlizing Corporation”, 14, Vitebskij av., Mogilev, Belarus, E-mail: indliz@mail.ru \\ ${ }^{2}$ Department of Mechanical Engineering Technologies, Lviv Polytechnic National University, \\ 12, S. Bandery Str., Lviv, Ukraine, E-mail: stupn@i.ua
}

\title{
INVESTIGATION OF THE CARBIDE-TIPPED TOOL WEAR HARDENED BY METHOD OF AERODYNAMIC IMPACT
}

Received: December 8, 2017 / Revised: December 25, 2017 / Accepted: December 26, 2017

(C) Zhygalov A., Stupnytskyy V., 2017

Abstract. Theoretical calculations and experimental studies of the influence of wear on the cutting process and the precision parameters of machining by hard alloys during milling are described in the article. The method of aerodynamic hardening is designed to increase the durability of tools, which are heterogeneous compositions of tungsten carbides, titanium and tantalum with cobalt ligature operating under severe process conditions with varying impact loads. The effect of hardening by the ADH method is achieved due to the influence of sound waves on the structure of hard alloys. The results of imitation studies of the wear process in the DEFORM system are described.

Keywords: cutting tools, wear, wear rate, method of aerodynamic hardening, simulation modeling, stress, deformation.

\section{Introduction}

The cutting tool life has a great influence on the productivity and machining costs, as well as on the achievement of precision and quality parameters of the machined surface layer, which determine the durability and efficiency of fatigue-free product's usage.

Tool life first of all depends on the wear of the cutting tool. This is the process of destruction of the solid body surface under the influence of another solid body and (or) the external environment. The wear of the cutting tool occurs as a result of chips friction to the rake face of the tool blade and of the flank surface to the machined workpiece. Wear is observed both on the rake and flank surfaces of the tool. For tools from hard alloys there is a characteristic wear on the main flank surface. This factor has the greatest influence on the accuracy of the workpiece. If that's the case, as well as for the most simple measurement, wear on the back surface $h_{z}$ can be used as main criterion of wear. The intensity of wear depends from multitude reasons: the tool material and properties, the dimensions and angles of the cutting edges of the tool, the mechanical properties of the workpiece material, the cutting modes (speed, feed, depth), cutting forces, temperatures and residual stresses in the machining area, coolant and other parameters [1].

As the maximum permissible wear, at which the tool loses its normal performance, we can use the wearing value at the transition point of the curve from the state of normal wear to the catastrophic wearing. This can be calculated on the basis of analysis of the tool wear kinetic curve that has three distinct periods (run-in, normal (steady-state) and catastrophic wear). When the extreme wear state of the tool's flank surface (blunting criterion) will be achieved, the cutting forces and the temperature in the machining zone will increase, the friction force will increases, the roughness and errors of the machined surface will increase too. When the wearing value reaches to the tool blunting criterion, the cutting process must be stopped, otherwise an uncontrolled change in the accuracy and quality of processing parameters will occur, a possibility tool breakdown will make, which can lead to the significant economic losses.

The study of the tool wear process is of great practical and theoretical importance because it contributes to the understanding and management of complex extreme processes of dependence of tool life 
from cutting modes. Based on the study of wear, it is possible to create new materials and properties of hard alloys, modern tool designs and techniques for using them to improve the efficiency of the cutting tool. Theoretical calculations of tool wear using a single formula do not exist to the present day. This is hampered by the extreme complexity of the cutting process and the wear mechanism, because there is a large number of interdependent factors. However, scientists have established the physical essence of the phenomenon of wearing process for various types of tool wear (abrasive, adhesive, diffusion, oxidative). Some mathematical equations that approximate the stability of a cutting tool operating under certain conditions can be obtained [2]. The most accurate results make it possible to calculate empirical dependencies by the method of full-factorial modeling of experimental data in specified ranges of tool operation with the specific processing conditions.

Dependence of wear $h_{z}$ is a function of time $\tau$, i.e. $h_{z}=f(\tau)$, and can be represented by the power equation:

$$
h_{z}=a \cdot \tau^{n}
$$

where $a$ and $n$ are empirical coefficients.

If we assume that the rate of tool wear is a constant value, then the parameters $a$ and $n$, which depend from such basic technological parameters as cutting speed $v$, feed rate $s$ and cutting depth $t$, can be described by the linear dependence and are represented as:

$$
\begin{aligned}
& a=a_{v} \cdot v^{2}+b_{v} \cdot v+a_{s} \cdot s^{2}+b_{s} \cdot s+a_{t} \cdot t^{2}+b_{t} \cdot t+C_{1} ; \\
& n=n_{v} \cdot v^{2}+d_{v} \cdot v+n_{s} \cdot s^{2}+d_{s} \cdot s+n_{t} \cdot t^{2}+d_{t} \cdot t+C_{2},
\end{aligned}
$$

where $a_{v}, b_{v}, a_{s}, b_{s}, a_{t}, b_{t}, n_{v}, d_{v}, n_{s}, d_{s}, n_{t}, d_{t}, C_{1}, C_{2}$ - empirical coefficients.

Then the formula (1) is transformed as:

$$
\tau=T=\left(\frac{h_{z}}{a}\right)^{(1 / n)} .
$$

Optimum cutting modes, at which the greatest resistance and the lowest wear are achieved, were determined by differentiating function (4) for each parameter.

For the face milling, the removal of the set allowance is due to the insertion of the tooth edge into the machined workpiece, to the displacement of some metal particles relative to others, the formation of chip elements and the separation of the formed chips from the machined layer. The processes of metal particle dislocation and the formation of chip elements, and therefore the change in the shape of the surface layers of the metal being machined, occur under the action of forces applied to the tooth of the milling cutter. On each contact tooth of the milling cutter, the forces of the cut layer resistance (Fig. 1): the tangential force $P_{t}$ and the radial force $P_{r}$. The forces $P_{t}$ and $P_{r}$ form a resultant force $R$, which can also be separated into two mutually perpendicular forces - in the longitudinal $P_{h}$ (horizontal) direction and in the transverse $P_{v}$ (vertical) direction. The normal (axial) force $P_{a}$ run in the direction of the spindle axis, which is used to overcome the friction elastic deformation of the outworn tool flank surface [2].

There is a relationship between the cutting forces $P_{h}, P_{v}$ and $R$, which is given in Table 1 [2].

Table 1

The ratio from the cutting force components for face milling

\begin{tabular}{|c|c|c|}
\hline \multirow{2}{*}{ Symmetrical milling } & \multicolumn{2}{|c|}{ Unsymmetrical milling } \\
\cline { 2 - 3 } & Down-milling & Up-milling \\
\hline$P_{h}=(0.40-0.50) R$ & $P_{h}=(0.60-0.90) R$ & $P_{h}=(0.30-0.50) R$ \\
\hline$P_{v}=(0.85-0.95) R$ & $P_{v}=(0.45-0.70) R$ & $P_{v}=(0.90-1.00) R$ \\
\hline$P_{r}=(0.50-0.55) R$ & $P_{r}=(0.50-0.55) R$ & $P_{r}=(0.50-0.55) R$ \\
\hline
\end{tabular}

The basic function of milling machines is to produce flat surfaces in any orientation as well as surfaces of revolution, helical surfaces and contoured surfaces of various configurations. Such functions 
are accomplished by slowly feeding the work piece into the equispaced multiedge circular cutting tool rotating at moderately high speed. Up milling needs stronger holding of the job and down milling needs backlash free screw-nut systems for feeding.
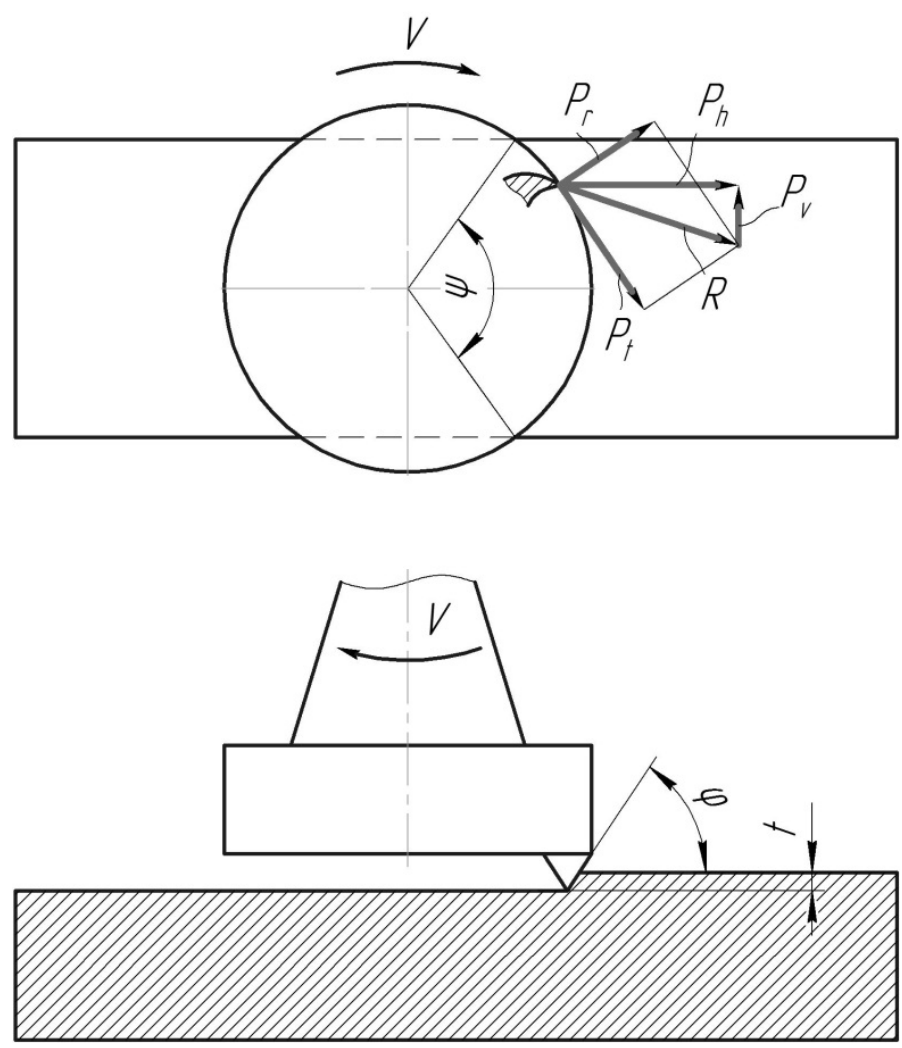

Fig. 1. Scheme of cutting forces for face milling

The tooth of the cutter is in contact with the workpiece in one turn a very short time $\left(10^{-2} \ldots 10^{-3} \mathrm{~s}\right)$. This is a feature of the milling process. There is quick heating and cooling of the tooth, which leads to a thermal shock, which adversely affects for the cutter's life. The cross-section of the cut layer during the milling is constantly changing, therefore the cutting forces change. Vibrations of the technological system appear. The tooth of the cutter runs into the workpiece and receives shock loads, which leads to increased wear of the cutter. In the case of conventional (up) milling, the phenomenon of the cutter's teeth slipping appears due to the presence of a radius on the cutting edge. Therefore, cutting begins with a small thickness of the cut, which leads to a decrease in resistance. For the conventional milling, the cutting forces try to tear the workpiece away from the machine table. As a result, the gaps between the guides increase, which leads to vibrations. For the climb (down) milling, the cutting forces press the workpiece to the machine table, there is no sliding phenomenon, which increases the tool life in 2-3 times, the roughness of the machined surface decreases [2].

The cutting force (shearing of the chips), and consequently the tool wear, is most affected by cutting forces in the longitudinal and transverse directions. The cutting process for workpiece with titanium alloy is interesting for such a demonstration [3]. As shown by the results of rheological modeling, the cutting forces in the transverse about the longitudinal direction change in dissonance at a high frequency (approximately $1.6 \mathrm{kHz}$ ). In the conditions of high-speed deformation of the material, the phenomenon of adiabatic shear takes place - the formation of local zones of increased plastic deformation, the energy of which is converted into thermal, which reduces the yield strength. When heat is actively released in a chipforming environment at a higher rate than its removal into the cooling medium due to thermal conductivity, the heat is concentrated near the glide planes, which contributes to the appearance of so-called adiabatic 
shear bands. This contributes to the destruction of the material along these strips and the formation of segmented shavings. At a certain moment $(t=1.16 \mu \mathrm{s})$, a transverse cutting force of the maximum value occurs. At the same time, the longitudinal cutting force assumes a minimum value. This stage of chip formation presupposes the prevalence of the compression process of the chip formation zone with the characteristic convexity of the chip root over the outer surface. At the moment of cutting $(t=1.35 \mu \mathrm{s})$, opposite phenomena occur: the transverse cutting force assumes a minimum value, and the longitudinal cutting force is the maximum value. This stage corresponds to the complete predominance of shear mechanisms of chip formation with a characteristic concavity of the chips along the outer surface. In a consequence, such stages are repeated, etc.

It is obvious, that the tool wear process greatly depends on elastic and plastic deformation, and on the change in longitudinal and transverse cutting forces.

The peripheral cutting force $P_{t}$ depends on the specific cutting pressure $p$, which is calculated as the cutting force per unit cross-sectional area of the sheared layer. In addition, this value depends on the average cross-section of the sheared layer $F_{s}$ as well as from the properties of the part's machined material:

$$
P_{t}=F_{s} \cdot p .
$$

The specific pressure $p$ depends from the part's machined material and from the thickness of the cutting layer: if the cutting layer will be thinner, then the specific cutting pressure will be greater, and vice versa.

The values of the specific cutting pressure $p$ for different materials, depending on the largest thickness $a_{\max }$ of the cut-off layer, are given in Table. 2. [2].

Table 2

Specific cutting pressure $p$ for milling

\begin{tabular}{|c|c|c|c|c|c|c|}
\hline \multirow{2}{*}{ Cutting layer depth $a_{\max }, \mathrm{mm}$} & \multicolumn{3}{|c|}{ Carbon steel $\left(\mathrm{kg} / \mathrm{mm}^{2}\right)$} & \multicolumn{3}{c|}{ Cast iron } \\
\cline { 2 - 7 } & $\sigma_{B}=60$ & $\sigma_{B}=75$ & $\sigma_{B}=75$ & $\mathrm{HB}=180$ & $\mathrm{HB}=180-200$ & $\mathrm{HB}=200$ \\
\hline 0.02 & $316-420$ & $525-635$ & $740-850$ & 210 & 305 & 420 \\
\hline 0.03 & $285-380$ & $475-570$ & $670-760$ & 184 & 264 & 367 \\
\hline 0.04 & $267-356$ & $455-535$ & $620-710$ & 163 & 235 & 326 \\
\hline 0.05 & $256-340$ & $425-520$ & $596-680$ & 154 & 222 & 308 \\
\hline 0.06 & $240-320$ & $400-480$ & $560-640$ & 142 & 205 & 285 \\
\hline 0.07 & $235-314$ & $392-470$ & $549-627$ & 135 & 195 & 271 \\
\hline 0.08 & $226-302$ & $376-452$ & $530-604$ & 129 & 186 & 259 \\
\hline 0.09 & $218-292$ & $364-432$ & $510-584$ & 126 & 182 & 253 \\
\hline 0.10 & $214-286$ & $358-428$ & $500-573$ & 122 & 175 & 244 \\
\hline
\end{tabular}

The average cross-section of the cut-off layer $F_{s}$ can be calculated by the formula:

$$
F_{s}=t \cdot a .
$$

where $t$ is the milling depth; $a$ is the thickness of the cut layer per tooth of the mill.

For different versions of face milling $F_{s}$ can be calculated as:

- for symmetrical cutting:

$$
F_{s}=0,5 \cdot t \cdot S_{t} ;
$$

- for incomplete symmetrical cutting:

$$
F_{s}=0,7 \cdot t \cdot S_{t} ;
$$

- for asymmetric cutting:

$$
F_{s}=0,5 \cdot t \cdot S_{t} \cdot \sin \psi ;
$$

- for end mills with an angular cutting edge:

$$
F_{s}=0,5 \cdot t \cdot S_{t} \cdot \sin \varphi,
$$

where $S_{t}$ is feed per teeth; $\psi$ is the contact angle of the tooth; $\varphi$ is the angle of the additional cutting edge. 
The normal force $P_{o}$, which acts on the wear face, depends from many factors of the cutting process such as stress, thermal, strain and from the technological parameters (roughness, accuracy, hardening of the surface layer, residual stresses, etc.). Calculation of these values is a rather difficult task, since the contact of the cutting tool with the workpiece along the wear face is accidental in connection with the continuous wear. Therefore, it is possible to calculate the forces and strains as probabilistic values only. Then the best option is to use analytical and numerical methods of calculation. Sufficiency and accuracy of calculations are defined as the degree of approximation of analytical results and experimental results. Such a model should, first of all, describe the physical nature of the occurrence of contact loads on the tool's wear face.

The main reason for the appearance of forces on the wear face is the elastic deformation of the workpiece material, which arises from the rounding of the blade of the cutting tool along the radius $r$ (Fig. 2). The blade does not completely convert the nominal shear layer with thickness $t$ into chips. A part of this layer with thickness $t_{c}$ passes into the chip, and the other part of the layer with thickness $t_{H}$ is not cut off, but deformed. When the blade moves, the cutting surface AM is gradually lowered by an amount $\mathrm{H}$ due to the elastic deformation of the workpiece. Then the machined workpiece exerts pressure on the wear face with a width $h_{w}$ and a length equal to the width of the cut layer $m$. Therefore, the blade can be considered as a punch pressed into the elastic half-space with the depth $H$. This value can be calculated if we assume that at the point $\mathrm{E}$, where the cut-off layer separates, the tangential stress $t_{c}$ coincides with the velocity vector $V$ and the angle with the resultant stress will be $45^{\circ}$ (the resultant stress is generated by the resultant force $P_{R}$, which consists of the radial $P_{r}$ and the tangent $P_{t}$ components) [4].

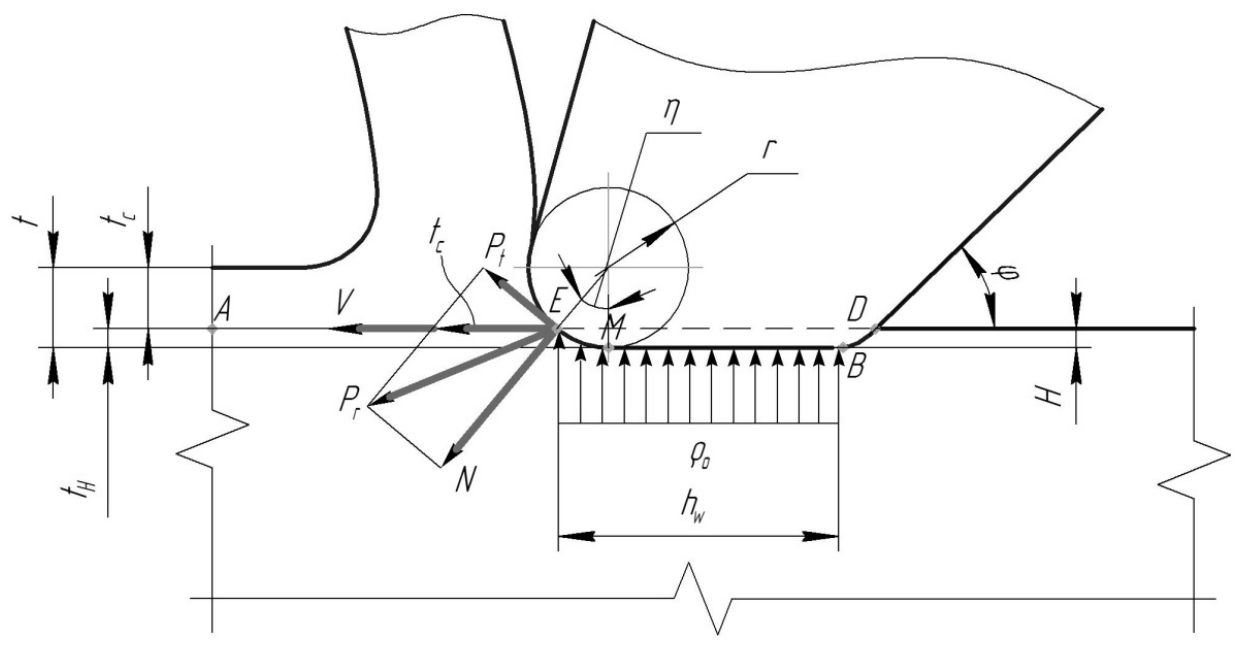

Fig. 2. Effects of forces and stresses in the contact zone of the cutting blade with the workpiece along the wear face

Modeling of wear on the flank surface can be done on the basis of solving the contact problem [5, 6] of the theory of elasticity [7]. However, these results reflect edge effects when indenting an absolutely rigid punch that simulates the blade of the cutting tool into an elastic half-space only. In this case, it is assumed, that at the point of chip separation from the workpiece on the cutting edge, the workpiece material (both not turning into chips or forming a chip at the rake surface of the cutting tool) is in a state of plasticity. At the same time, this condition should not be considered obligatory, since the material is separated at a given point and the connection between the chips and the body of the workpiece is broken. The depth of indentation of the punch, which determines the force of the indentation, is also not taken into account [8].

One can take the average value of the normal cutting force based on the calculation of the probability function [4]:

$$
P_{o}=\frac{E \cdot H}{2\left(1-v^{2}\right)} \cdot\left(\frac{2}{\sqrt{\pi}} \cdot \sqrt{m \cdot h_{w}}+m^{0,64} \cdot h_{w}^{0,36}\right),
$$


where $E$ is modulus of elasticity:

$$
E=\frac{\mu \cdot(3 \lambda+2 \lambda)}{\lambda+\mu}
$$

$v$ is Poisson's ratio:

$$
\begin{gathered}
v=\frac{\lambda}{2(\lambda+\mu)} ; \\
H=r \cdot(1-\cos \eta)=r \cdot\left[1-\frac{(1+\mu)}{\sqrt{2 \cdot\left(1+\mu^{2}\right)}}\right] ; \\
\lambda=\frac{E \cdot v}{(1+v) \cdot(1-2 \cdot v)} ; \\
\mu=\frac{E}{2 \cdot(1+v)},
\end{gathered}
$$

where $\eta$ is contact angle between the tooth blade and the workpiece layer which will be performed by elastic deformation.

Then, in the process of cutting with the formation of wear $h_{w}$, in each time $\tau$, taking into account (1), the cutting force $P_{o(\tau)}$ will be:

$$
P_{o(\tau)}=\int_{0}^{\tau} \frac{E \cdot H}{2 \cdot\left(1-v^{2}\right)} \cdot\left(\frac{2}{\sqrt{\pi}} \cdot(m \cdot a)^{0.5} \cdot \tau^{0.5 \cdot n}+(m \cdot a)^{0.36} \cdot \tau^{0.36 \cdot n}\right) d \tau .
$$

A change of the value of the force $P_{o(\tau)}$ will lead to an elastic outpress $y_{\tau}$ of the cutting tool in the direction of the normal cutting force action (taking into account the rigidity of the technological system $j$ ) [9]:

$$
y_{\tau}=\frac{P_{o(\tau)}}{j} .
$$

Cutting process will be modeled taking into account the outpressing value $y_{\tau}$ and the wear $h_{w}$ in the direction of the normal force action:

$$
y=h_{w(\tau)} \cdot \sin \varphi_{3}+\frac{P_{o(\tau)}}{j} .
$$

Taking into account (5), (6), (18), the peripheral cutting force $P$ at any time $\tau$ can be calculated by the formula:

$$
P_{\tau}=\left(t-h_{w(\tau)} \cdot \sin \varphi_{3}-\frac{P_{o(\tau)}}{j}\right) \cdot s_{t} \cdot p .
$$

Then, taking into account the data of Table 1 and formulas (7) - (10), (19), the cutting forces in the longitudinal $P_{h}$ and in the transverse $P_{v}$ directions can be calculated as:

$$
\begin{aligned}
& P_{h(\tau)}=k_{l} \cdot\left(t-h_{w(\tau)} \cdot \sin \varphi_{3}-\frac{P_{o(\tau)}}{j}\right) \cdot s_{t} \cdot p ; \\
& P_{v(\tau)}=k_{t} \cdot\left(t-h_{w(\tau)} \cdot \sin \varphi_{3}-\frac{P_{o(\tau)}}{j}\right) \cdot s_{t} \cdot p,
\end{aligned}
$$

where $k_{l}$ and $k_{t}$ are coefficients (Table 1), which relate the cutting forces $P_{h}, P_{v}$ and $P_{\tau}$. 


\section{Description of the Aerodynamic Hardening Method}

The aerodynamic hardening method $(\mathrm{ADH})$ [10] is designed to increase the durability of tools, including those made from hard alloys, which are heterogeneous compositions of tungsten carbides, titanium and tantalum with cobalt ligature operating under severe process conditions with varying impact loads.

The effect of hardening by the ADH method is achieved due to the influence of sound waves on the structure of hard alloys. In machined hard alloys, the carbide phases are grinded and redistributed, the dislocations of the internal structure decrease as a result of self-organization at the level of the crystal lattice. The transition from disorderly motion of fluctuations and their chaotic state to a new order is ensured. The parameters of the structure of materials for the given operating conditions of parts are improved [11]. At a number of engineering plants in production conditions it was established that when hardening by the ADH method, the durability of a carbide tool working with impact loads increases by 2-3.5 times [12].

\section{Discussion of Research Results}

Empirical dependencies, determined by the method of full-factorial simulation of experimental studies in the specified ranges of tool operation in the steel AISI 1045 machining for hard alloys MC111 and MC131 (according to the classification from Sandvik Coromant Co. (Sweden)), unhardened and hardened by ADH method were obtained. Dependence of flank surface wearing $h_{r}$ and tool life value $T$ from the technological modes, as well as the optimal values of these modes, are given in Table 3.

Fig. 3 shows the diagrams of the flank surface wear $h_{r}$ for the alloys MC111 and MC131, constructed according to the empirical formulas (Table 3) under the following modes: $V=140 \mathrm{~mm} / \mathrm{min}$; $S=0.1 \mathrm{~mm} /$ tooth; $t=1.0 \mathrm{~mm}$.

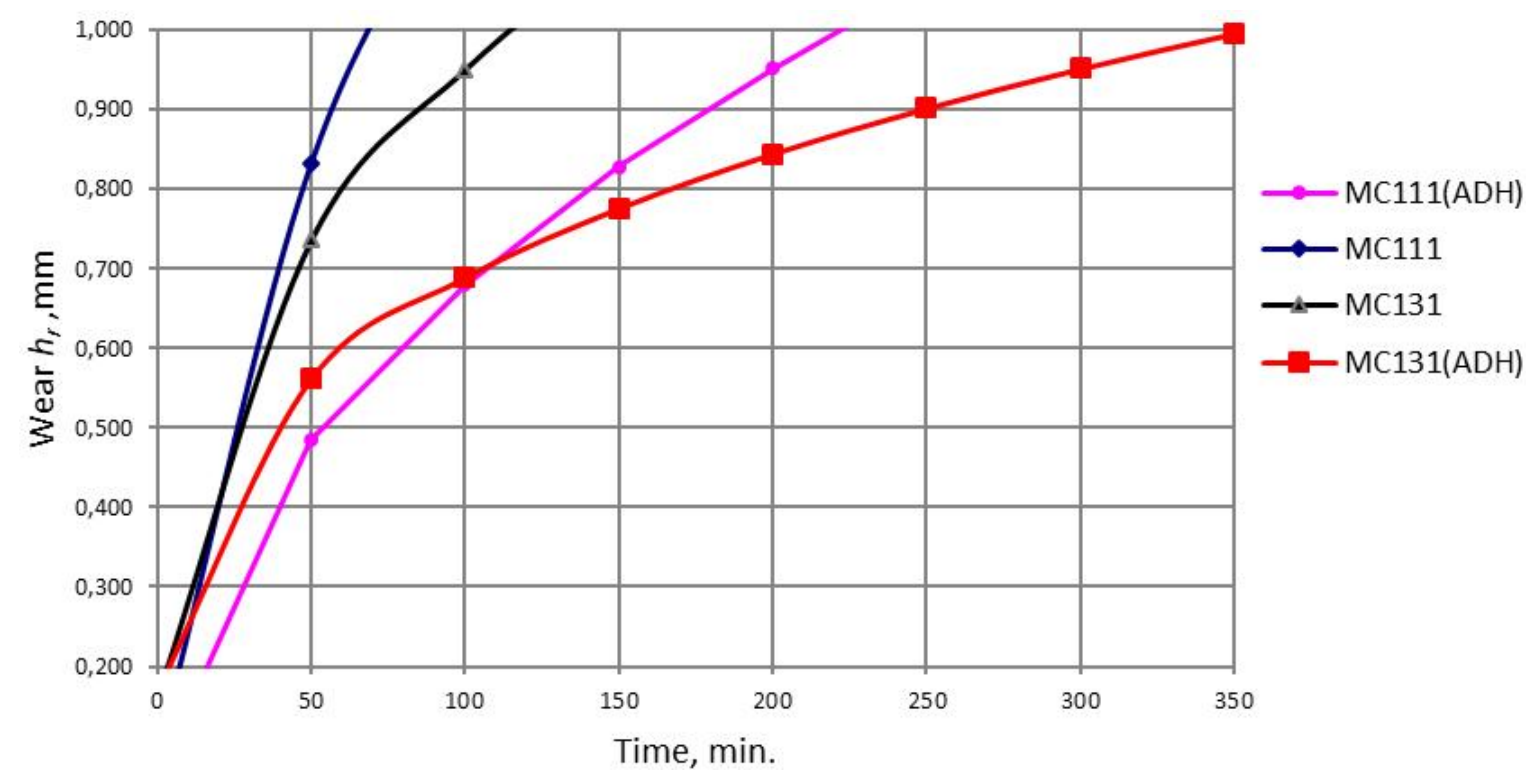

Fig. 3. Dependence of wear hz on the flank surface for alloys MC111 and MC131 (ADH-hardened), constructed from empirical relationships from Table 3 for modes:

$V=140 \mathrm{~mm} / \mathrm{min} ; S=0.1 \mathrm{~mm}$ per tooth $t=1.0 \mathrm{~mm}$

When milling, the cutting tool that works with impact loads wears more intensively than with constant cutting (turning). This is because, in addition to adhesive and diffusion wear, the number of cyclic influences on the tool is strongly influenced. Therefore, the fact that hardening of hard alloys by the ADH method increases the impact strength by 25-35\%, the impact resistance of hard alloys strengthened by the ADH method is increased by at least $30 \%$. Therefore, when rough machining of the low-alloyed steels 
with hard alloys, the wear's criterion will be: for unreinforced materials $-h_{r}=0.8 \mathrm{~mm}$, hardened materials by the ADL method $-h_{r}=1.0 \mathrm{~mm}$. For finish machining, wear's criterion will be as a measure of wear $h_{r}=0.4-0.5 \mathrm{~mm}$.

Table 3

Wear formulas for the flank surface $h_{r}$ and tool life $T$

for alloys MC111, MC131, unhardened and hardened

by ADH method for machining of the workpiece made of steel AISI 45

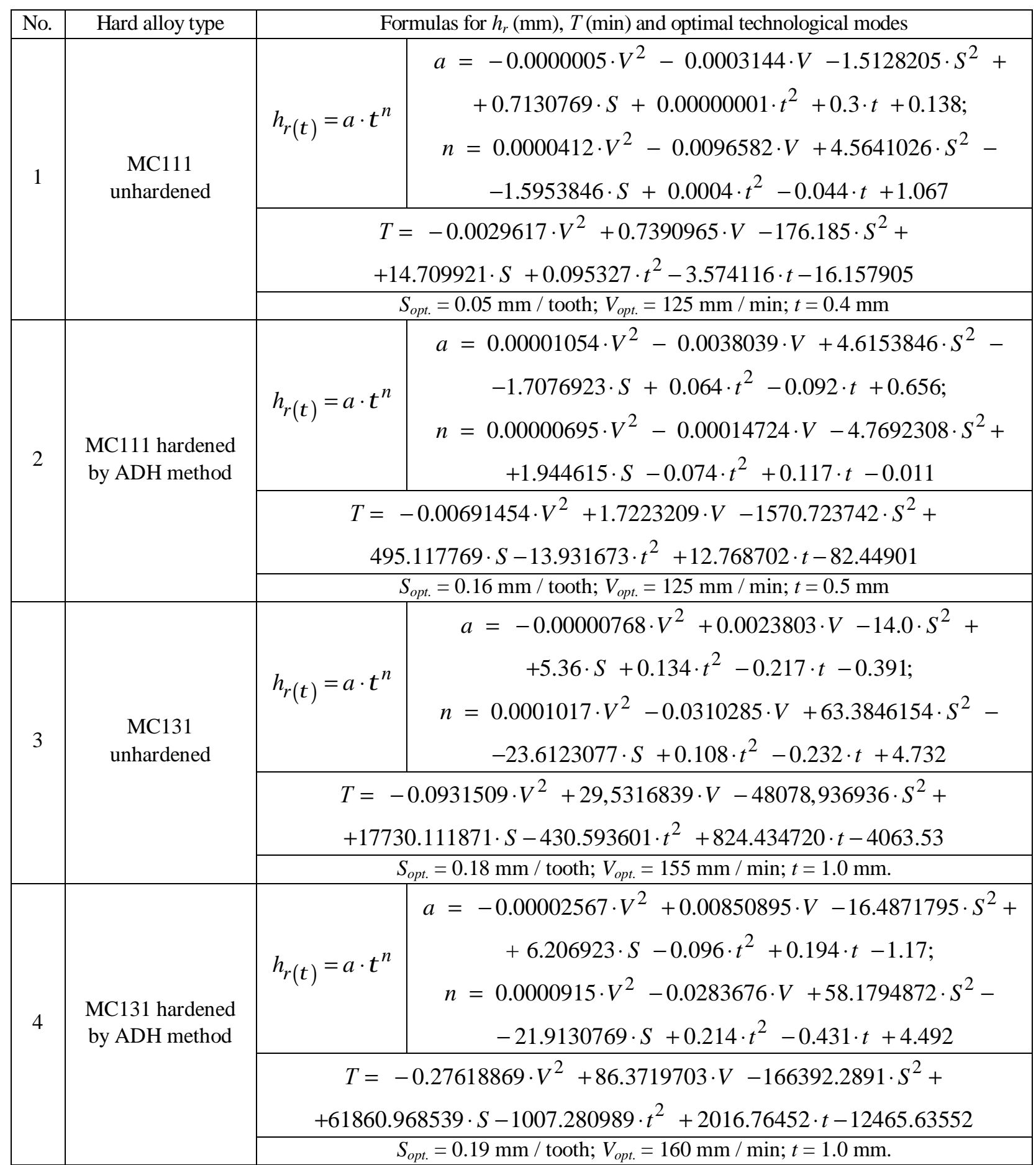

Thus, the number of single and interconnected parameters has a great influence on the wear process of the cutting tool. 
When designing modern high precision and efficient processing technologies, it is necessary to take into account a large number of factors that influence to such processes. They must take into account not only the standards of accuracy and the quality of the machined surfaces set by the designer, but also ensure the operational properties of products, such as wear resistance, fatigue strength, corrosion resistance, tribotechnical quality characteristics of movable joints, and so on. However, it is difficult to describe the interrelationships of these factors at the design stage of technological processes due to the lack of theoretical information. The systemic principle of the product's life cycle realizing requires a direct link between the technological stage and the operational stage, and not only their indirect communication through the provision of conditions and constraints formulated at the design stage. Especially big problems arise when new processes planning, which are difficult to adapt to the development of technological processes for the manufacture of products. This is the main deterrent to the introduction of new technologies in production.

The existing integrated CAD/CAM systems (as part of PLM-system), which based on mathematical, empirical and analytical algorithms, describing known principles and interrelationships in technological processes, allow modeling in accordance with the generalized algorithm of the Computer-Aided-Forming (CAF) system functioning. The results of the analysis of the stress-strain state of surfaces in the course of their shaping make it possible to model the microtopology of surfaces, residual stresses and deformations, and also to form prognostic links between the structure and parameters of the technological process and the dominant operational properties of the parts [3].

At the same time, for the integrated provision of the life cycle of engineering products, the creation of which is provided by new methods of machining, tools or technologies, is a necessary condition for the creation and implementation of scientific and applied fundamentals of functionally-oriented process planning for new technologies.

The methodology of function-oriented design is based on the CAPE (Concurrent Art-to-Product Environment) concurrent engineering system with parametric links between model elements and software modules. The multilayered digital product model and the coordination functions of the CAPE-system make it possible to significantly shorten the product creation cycle, using new technologies, improve the technical level of projects, avoid errors due to interconnection and controllability of information at all stages of technological planning process.

The using of the CAF-system is a main feature of functionally-oriented technologies for effective implementation of the PLM-methodology in mechanical engineering which based of the principle of concurrent design. The main characteristic of this system is analysis of the rheological model of technological steps simulation and the complex of functional modules and analytical applications for the formation of precision, thermodeformational, microgeometric and structural-phase parameters of the machined surfaces.

The CAF-system complements the existing integrated complex of CAD/CAE/CAPP/CAM systems, providing a predictive ability to simulate and establish the dependence of the main qualitative product's indicators from the structure and parameters of the machining technological process [14].

The basic functionally oriented technological process planning methodology involves solving a number of problems associated with adequate simulation modeling of internal structural processes that have a significant influence on the shaping and quality parameters of the products manufactured.

In Figs. 4-5 the feed $P_{f}$ and back $P_{b}$ components of the down and up milling forces received as a result of the hard alloy MC131 machining simulation from steel AISI 45 with the cutting modes: cutting speed $V=158.3 \mathrm{~m} / \mathrm{min}$, feed per tooth $S=0.12 \mathrm{~mm}, t=1.0 \mathrm{~mm}$ are shown.

The modeling of the cutting tool wearing process in the DEFORM system (Fig. 6) is based on the calculation of the Usui criterion [14]:

$$
w=\int a \cdot p \cdot V \cdot e^{-b / T} d t,
$$

where $p$ is interface pressure; $V$ is sliding velocity; $T$ is interface temperature (in degrees absolute); $d t$ is time increment; $a, b$ are experimentally calibrated coefficients.

Thus, the results of modeling the interface pressure, sliding velocity, and interface temperature are necessary for the tool wear rate modeling. The results of modeling these quantities in Fig. 7, $a-c$ for milling of the carbon steel AISI 45 by unhardening hard tool alloy MC131 are shown. 


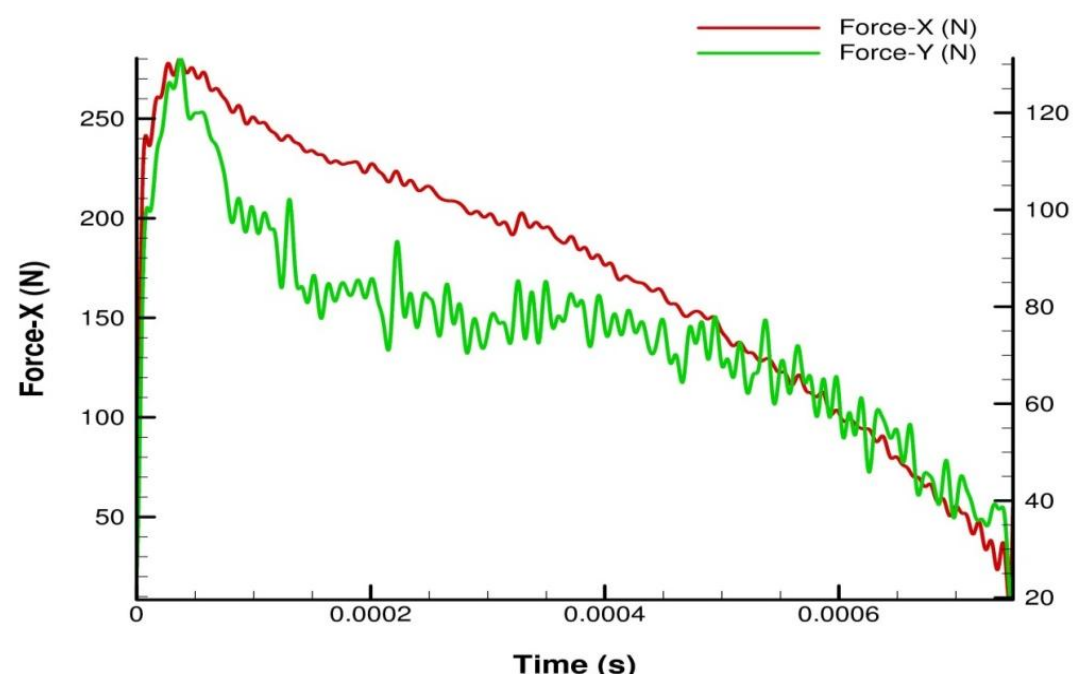

Fig. 4. Back $P_{b}$ (Force $\left.X\right)$ and feed $P_{f}$ (Force $\left.Y\right)$ components of the climb (down) milling forces which are modeled by the AdvantEdge system (tool - hard alloy MC131; workpiece - steel AISI 45; for modes: cutting speed $V=158.3 \mathrm{~m} / \mathrm{min}$, feed per tooth $S=0.12 \mathrm{~mm}$, depth $t=1.0 \mathrm{~mm}$ )

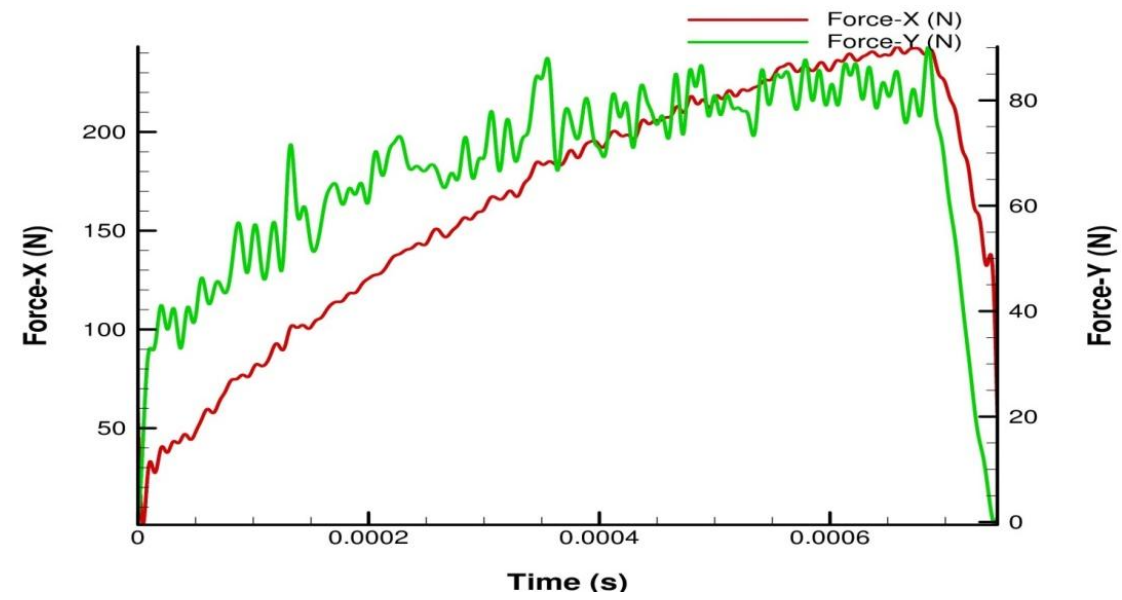

Fig. 5. Back $P_{b}($ Force $X)$ and feed $P_{f}($ Force $Y)$ components of the conventional (up) milling forces which are modeled by the AdvantEdge system (tool - hard alloy MC131; workpiece - steel AISI 45; for modes:

cutting speed $V=158.3 \mathrm{~m} / \mathrm{min}$, feed per tooth $S=0.12 \mathrm{~mm}$, depth $t=1.0 \mathrm{~mm}$ )

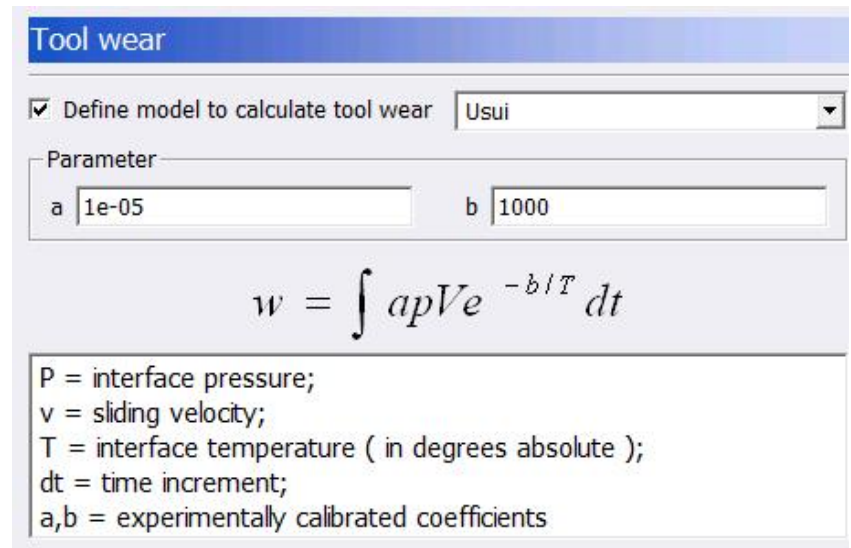

Fig. 6. Dialog window for setting of the initial data for modeling of the cutting tool wear 


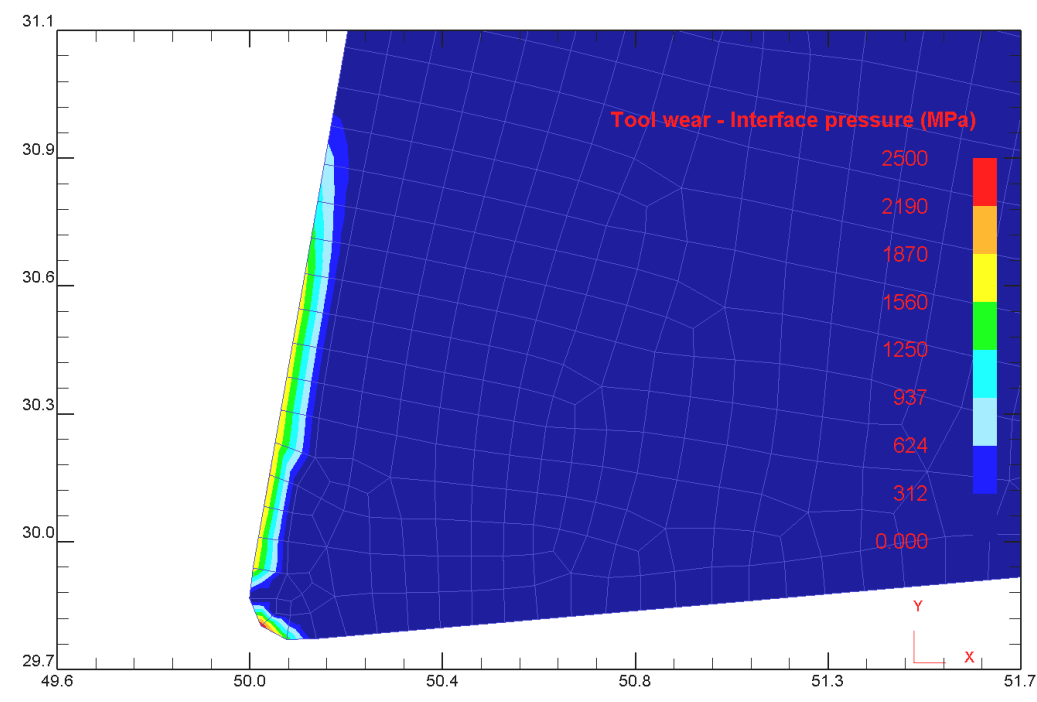

$a$
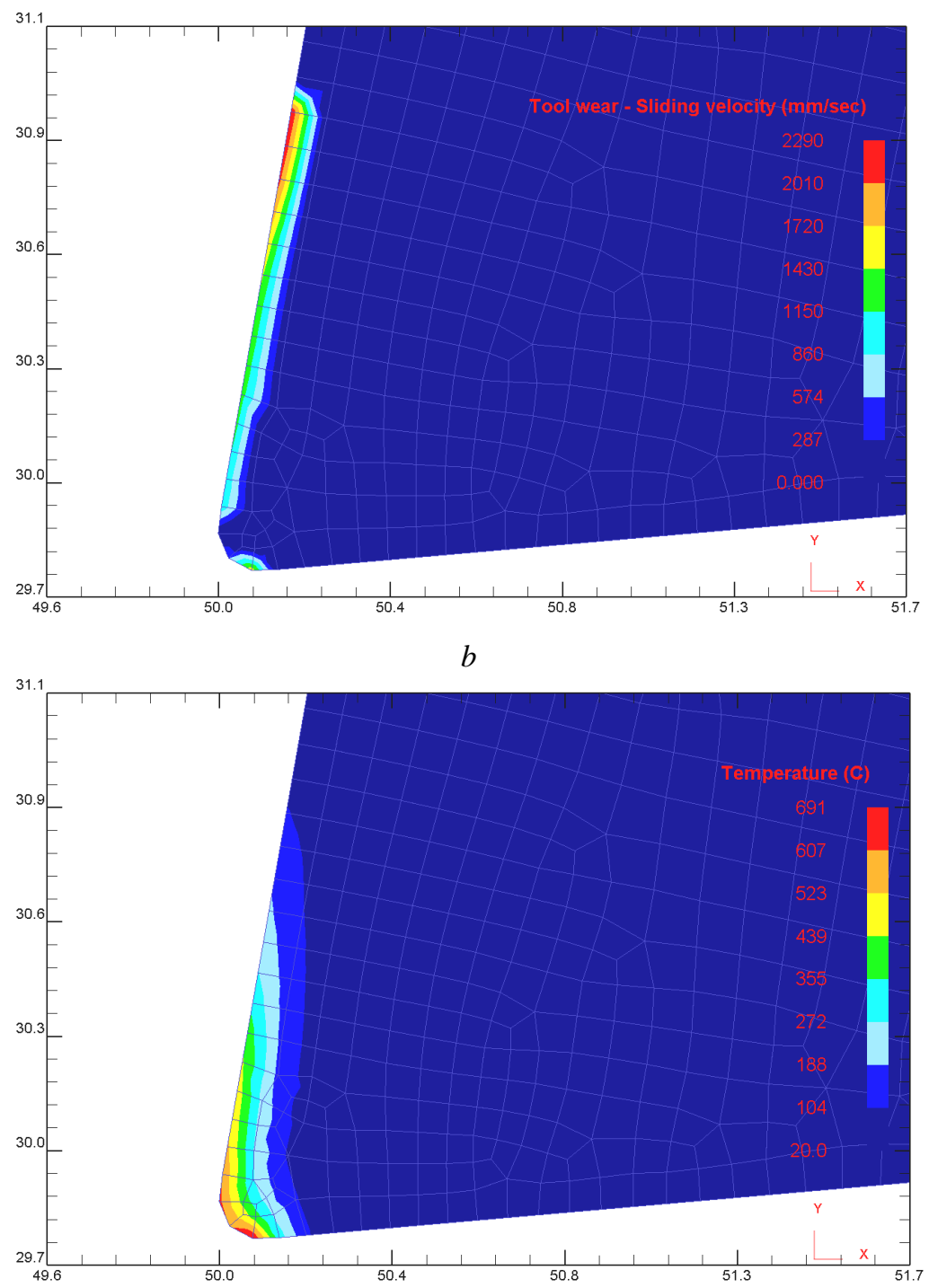

$c$

Fig. 7. Results of modeling the interface pressure (a), sliding velocity $(b)$, and interface temperature (c) for milling of steel AISI 45 by unhardening hard tool alloy MC131 (cutting modes: cutting speed $V=158.3 \mathrm{~m} / \mathrm{min}$, feed per tooth $S=0.12 \mathrm{~mm}$, depth $t=1.0 \mathrm{~mm}$ ) 
In Fig. 8 the results of the tool wear rate modeling, as a result of simulation modeling in the DEFORM 2D system are shown. You can see, that wear rate for unhardened tool material is about $60 \%$ more than the tool wear rate, which is hardened by the ADH method.
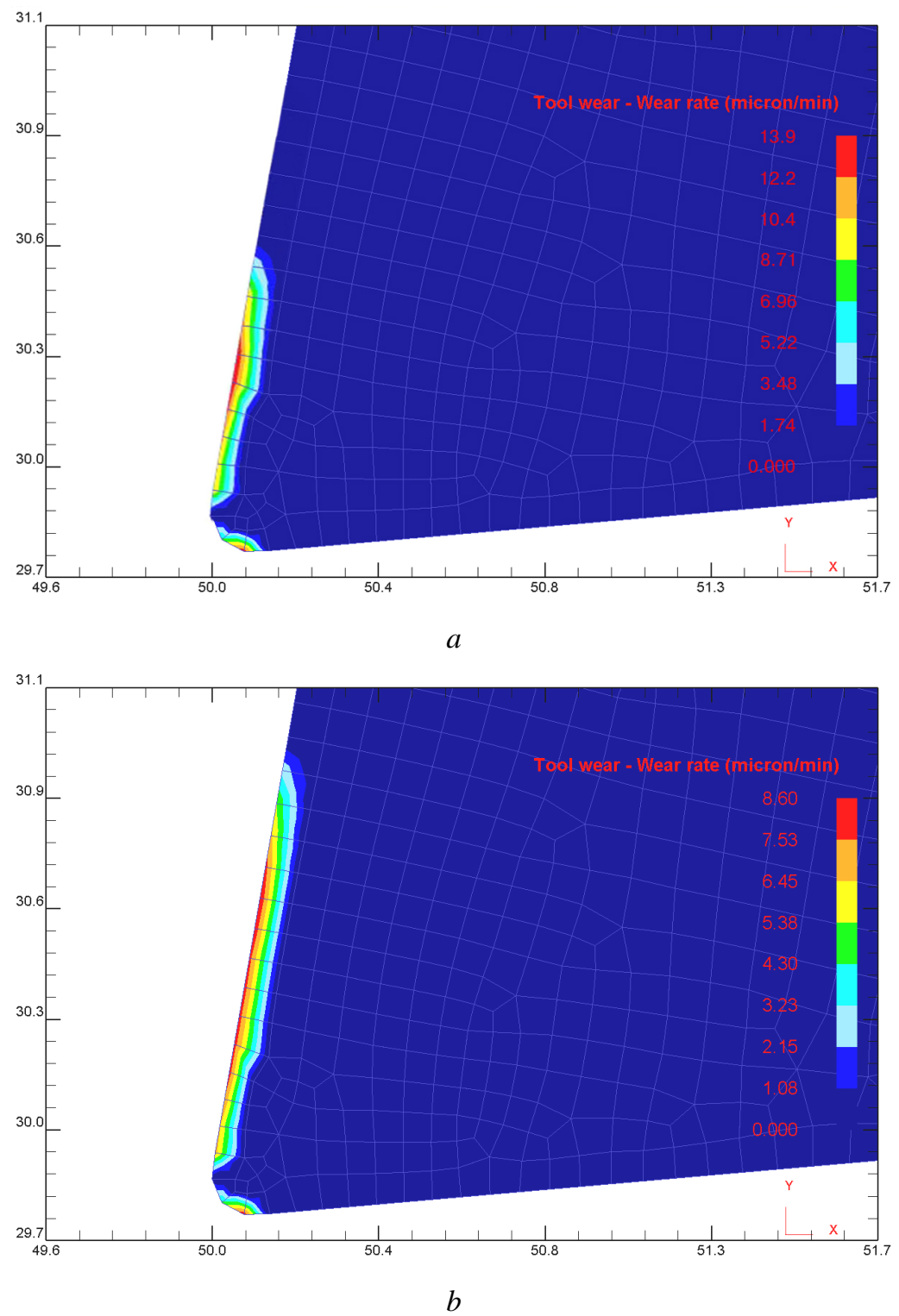

Fig. 8. Results of unhardened (a) and hardened by ADH method (b) tool wear rate modeling for the workpiece's machining made of steel AISI 45

(cutting modes: cutting speed $V=158.3 \mathrm{~m} / \mathrm{min}$, feed per tooth $S=0.12 \mathrm{~mm}$, depth $t=1.0 \mathrm{~mm}$ )

Taking into account the peculiarities of the wear process discussed above for cutting solid alloys, including hardened by the ADH method, the physical essence of the cutting process formulated in [13] is confirmed. First, the tool cuts into the workpiece material, and under its action, plastic deformation of the metal layer occurs, which is accompanied by the absorption of external energy. The cut-off metal layer becomes stronger and becomes brittle. Then shear process is appear and the chip element is formed. The heat of cutting is concentrated in the area of chip separation as a result of low thermal conductivity of the machined material. This promotes to the activation of adhesion and diffusion processes, causing destruction of the cutting edges of the tool. These phenomena, together with the increased abrasive and mechanical properties of hard alloys under impact loading, intensify the process of wear of the cutting edge of the milling tool. At the same time, the amplitude variations of the feed and back forces increase by 
approximately 2.0 times compared to the stable cutting (for example, turning). This is the cause of high wear, as well as the reduced resistance of the cutting tool.

\section{Conclusions}

1. The wear process is one of the main factors affecting the cutting process. Theoretical calculations and experimental studies of the wear effect on the cutting process and the precision parameters of machining by hard alloys during milling have shown that the wear process of the cutting tool is influenced by large number of single and interconnected parameters, which cannot be analytically fully taken into account without computer simulation.

2. The results of imitation studies of the wear process in the DEFORM system showed that machining of workpieces with steel AISI45 by tools with ADH hardened alloy $(\mathrm{v}=158.3 \mathrm{~m} / \mathrm{min}$, $\mathrm{s}=0.12 \mathrm{~mm} /$ tooth, $\mathrm{t}=1.0 \mathrm{~mm}$ ) increases tool life by approximately $60 \%$.

\section{References}

[1] G. I. Granovskij and V. G. Granovskij, Rezanie metallov [Metals Cutting]. Moscow, Russia: Vysshaja shkola Publ., 1985. (In Russian).

[2] Vadym Stupnytskyy and Andrij Kuk, "Determination of deformation component roughness parameters using the methods of rheological simulation modeling of the cutting process", Austrian Journal of Technical and Natural Sciences, no. 3, section 4, pp. 33-37, 2014.

[3] V. Stupnytskyy, "Issledovanie adiabaticheskogo sdviga struzhki pri mehanicheskoj obrabotke titanovyh i nikelevyh splavov na osnove analiza rezul'tatov imitacionnogo reologicheskogo modelirovanija v sisteme DEFORM" ["Study of adiabatic chip shift during machining of titanium and nickel alloys on the basis of analysis of the results of imitative rheological modeling in the DEFORM system"], Nauchnyj (proizvodstvenno-prakticheskij) zhurnal "Vesnik Grodzenskaga Dzjarzhawnaga Wniversitjeta Imja Janki Kupaly”, no. 3 (158), issue 6, pp. 76-86, 2013. (In Russian).

[4] G. S. Zheleznov, "Ocenka sil, dejstvujushhih na faske iznosa instrumenta po zadnej poverhnosti" ["Evaluation of forces acting on the tool wear face on the back surface"], Stanki i instrument [Machines and tools], no. 6, pp. 1-3, 2003. (In Russian).

[5] Vadym Stupnytskyy, "Investigation of the influence of machining factors on the workpiece deformation mode in the chip-forming zone by the finite element method", Ukrainian Journal of Mechanical Engineering and Materials Science, vol. 2, no. 2, pp. 61-70, 2016.

[6] V. L. Strel'cov, "Issledovanie processa kontaktirovanija zadnej poverhnosti rezhushhego instrumenta s obrabatyvaemoj poverhnost'ju" ["Investigation of the process of contacting of the back surface of the cutting tool with the surface being machined"], Vestnik mashinostroenija [Bulletin of Mechanical Engineering], no. 10, pp. 38-41, 2001. (In Russian).

[7] I. Ja. Shtaerman, Kontaktnaja zadacha teorii uprugosti [The contact problem of the theory of elasticity]. Moscow, Russia: Gosudarstvennoe izdatel'stvo Tehniko-teoreticheskoj literatury Publ., 1949. (In Russian).

[8] L. A. Galii, Kontaktnye zadachi teorii uprugosti $i$ vjazkouprugosti [Contact problems of the theory of elasticity and viscoelasticity]. Moscow, Russia: Nauka Publ., 1980. (In Russian).

[9] A. N. Zhigalov, Adaptivnoe upravlenie pri sovmeshhennoj obrabotke rezaniem i PPD [Adaptive control with combined machining and PPD]. Mogilev, Belarus: MGUP Publ., 2013. (In Russian).

[10] A. N. Zhigalov, G. F. Shaturov and V. M. Golovkov, "Sposob ajerodinamicheskogo uprochnenija izdelij" ["Method of aerodynamic hardening of products"], BY Patent 21049, June 30, 2017. (In Russian).

[11] A. N. Zhigalov, A. R. Maslov and G. F. Shaturov, "Improved Hard Alloys for Efficient Milling", Russian Engineering Research, vol. 35, no. 11, pp. 818-821, 2015.

[12] A. R. Maslov and A. N. Zhigalov, "Povyshenie soprotivlenija iznashivaniju tverdyh splavov metodom ajerodinamicheskogo vozdejstvija" ["Increasing of wear resistance of hard alloys by the method of aerodynamic action"], Trenie i iznos [Friction and wear], vol. 35, no. 5, pp. 461-466, 2014. (In Russian).

[13] P. I. Jashhericyn, E. Je. Fel'dshtejn and M. A. Kornievich, Teorija rezanija [Theory of cutting]. Minsk, Belarus: Novoe znanie Publ., 2006. (In Russian).

[14] Vadym Stupnytskyy, "Computer Aided Machine-Building Technological Process Planning by the Methods of Concurrent Engineering", Europaische Fachhochschule: Wissenschaftliche Zeitschrift, vol. 2, no. 3, section 1, pp. 50-53, 2013. 